Volumen 17 n $^{\circ} 32014$

\title{
Editorial
}

\section{Experiencia, Investigación e Innovación}

\author{
Rodolfo Crespo Montero \\ Director de la revista "Enfermería Nefrológica" \\ Hospital Universitario Reina Sofía. Facultad de Medicina y Enfermería de Córdoba
}

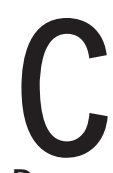

on este atractivo lema, nos recibirá Toledo del 15 al 17 de Octubre en el que será, el XXXIX Congreso Nacional de la SEDEN. Pocas las sociedades científicas de enfermería pueden presumir de cumplir 39 años y aglutinar a cerca de 1500 enfermeras/os, como socias/os. Durante varias décadas, nuestros antecesores, se han encargado de recordar un pasado sin el cual no habría presente, ni se podría proyectar el futuro. De manera breve, concisa y con el corazón, nos han ido recordando la gran dosis de ilusión y motivación que impulsó a un grupo de enfermeras/os a la creación, mantenimiento y crecimiento de nuestra sociedad, con un esfuerzo y dedicación casi artesanal, por la escasez de medios.

Este grupo de enfermeras y enfermeros que hicieron posible la realidad que es hoy la SEDEN, nunca se circunscribió sólo a la junta directiva. Siempre ha habido un importante grupo de colaboradores que "ha sentido" a la SEDEN como algo muy suyo, que no sólo ha colaborado en los diferentes proyectos que se han ido desarrollando a lo largo de estos años, sino que su aportación ha sido más importante, ha conformado un grupo de opinión fundamental, con mucho peso específico. Su influencia ha permitido que las diferentes juntas directivas hayan cometido pocos errores importantes en el devenir de los acontecimientos de la Sociedad. Este grupo ha tenido otra misión clave, asumir cargos directivos desde la experiencia atesorada en la cercanía a sus antecesores.

Obviamente, siendo este un análisis muy personal, creo que ha sido el mecanismo de mayor relevancia, en el relevo generacional de los cargos electos. Sin embargo este modelo está agotado: Desde hace 4-5 mandatos, la Junta Directiva en ejercicio tiene que prorrogar el mandato por no haber candidaturas a la finalización del mismo, teniendo que asumir un año de prórroga para el cual no se habían presentado; algo que puede resultar contradictorio, en una sociedad tan activa y que goza de tan buena "salud" a todos los niveles.

Por tanto, cabe preguntarse que ha ocurrido en los últimos años, para que el relevo no se haya producido de manera más "natural". A mí se me ocurren varias respuestas:

- El escaso relevo generacional acontecido en las unidades nefrológicas de los centros públicos, con el consiguiente cansancio profesional y escasa entrada de savia nueva con ilusión y motivación para implicarse en proyectos de futuro.

- Los centros públicos, organizaciones ideales hasta hace unos años, para compatibilizar puestos de gestión o asistenciales, con cargos directivos en la Sociedad, ya no son lo que eran. Los rigores presupuestarios y de gestión, el envejecimiento de las plantillas, la escasa cobertura del absentismo y un sinfín de problemas cotidianos, dejan poco margen a las supervisoras/es para aventurarse en su tiempo libre en otra gestión, menos exigente en el día a día, pero con toma de decisiones que pueden ser transcendentales para el colectivo. $\mathrm{Ni}$ que decir tiene que además, desde las direcciones de enfermería, no solo no se colabora, sino que se obstaculiza. Más complicado aún lo tienen las/os enfermeras/os asistenciales.

- El relevo generacional se ha producido exclusivamente en los centros concertados de diálisis, en los cuales las plantillas están muy ajustadas y las dificultades para acometer otras empresas que no 
sean meramente las laborales, son muchas. Todos sabemos de la necesaria colaboración de nuestra empresa, para poder cumplir con las obligaciones a que está sujeta la junta directiva.

- Evidentemente, ocupar un cargo en la junta directiva siempre es motivo de orgullo y reconocimiento profesional, pero el nivel de exigencia es alto. Aun contando con toda la infraestructura que tiene hoy la SEDEN, este desempeño no está exento de dificultades, trabajo, dedicación y lo más importante, toma de decisiones.

No obstante, siempre aparece un grupo de compañeras o compañeros, que en un ejercicio de "sacrificio por los demás", pondrá su tiempo y conocimiento al servicio de la esta sociedad, cuando ya no quede más remedio, es decir, cuando la Junta saliente haya prorrogado el año que contemplan los estatutos de la Sociedad.
Sirva esta reflexión apara recordar que la actual Junta Directiva acaba ciclo el año que viene después de 2 mandatos, y no sería justo "premiarles" con otro año de "castigo". Sería conveniente y todo un ejemplo de participación comprometida que hubiera al menos una candidatura para el año 2015.

Espero que los que tengamos la oportunidad de asistir a este Congreso apreciemos el trabajo conjunto que han desarrollado Comité Organizador y Junta Directiva, para ofrecernos un programa atractivo y equilibrado, con una mezcla de Conferencias, Mesas Redondas, Cursos y Comunicaciones Libres.

Gracias por vuestro trabajo. 